\title{
KNOWLEDGE, ATTITUDE AND PRACTICE ON EXPOSURE TO BISPHENOL A AMONG DENTAL SURGEONS IN SOUTHERN INDIA
}

\author{
Harshit Atul Kumar ${ }^{\circledR}$, Crystal Runa Soans ${ }^{\circledR 2}$, PS Murali', MS Ravi², Keerthan Shashidhar ${ }^{2}$, Shalin Shersha ${ }^{2}$ \\ ${ }^{1}$ Department of Orthodontics and Dentofacial Orthopedics, Manipal College of Dental Sciences, Mangalore, \\ Manipal Academy of Higher Education, Manipal - 576104, India \\ ${ }^{2}$ Nitte (Deemed to be) University, AB Shetty Memorial Institute of Dental Sciences, \\ Department of Orthodontics and Dentofacial Orthopedics, Mangalore, India
}

\begin{abstract}
Background. Bisphenol A (BPA) is a product in the manufacture of Bis-GMA, which is commonly used in dentistry, and is known to have a number of adverse effects.

Objectives. The aim of this study is to evaluate to assess the knowledge, attitude and practice based on exposure and handling of BPA containing materials among dental surgeons for better understanding about the level of care rendered to the patients.

Material and methods. A questionnaire survey was conducted on 400 dental surgeons in Southern India. The questionnaire consisted of 20 objective type questions out of which ten questions assessed knowledge and five questions assessed the attitude and five questions to understand the practice related measures taken by the dentist. The data collected were analysed using SPSS version 23.

Results. A total of 402 responses were collected for this online questionnaire survey over a period of 2 months. It was found that females showed higher knowledge and attitude towards exposure to BPA which was statistically significant when compared to males. It showed that dentists with more than 20 years of practice had a higher level of knowledge. Though most of the groups agreed fairly on safety practice to be undertaken related to BPA exposure in their clinics, the ones with experience more than 20 years displayed the least positive attitude and dentists with 6-10 years of practice had the least positive behaviour among all.

Conclusions. In spite of having a good knowledge regarding the harmful effects of BPA, dental surgeons are not very cautious while using materials containing them on a regular basis. Therefore, there is a need to enhance the awareness with the help of Continuing Dental Education programs or proper instructions on the packaging.
\end{abstract}

Key words: knowledge, attitude, practice, Bisphenol A, composite, dental surgeons

\section{INTRODUCTION}

Bisphenol A (BPA) is a by-product during the manufacture of polycarbonate plastics and epoxy resins, which play an important role in food and drink packaging. Although diet is a major source of BPA exposure in most people; air, dust, and water and direct skin contact are others. BPA can leach out from containers with internal epoxy resin coatings or products made of polycarbonate plastic such as baby bottles, tableware, food containers, and water bottles into the products that we consume. Leaching of BPA depends more on the temperature of the liquid than the age of the container ie. more migration with higher temperatures $[8,17]$.
BPA plays an important role in dentistry. It is the main raw material for Bis-GMA and polycarbonate products. Generally, the molecules with a double benzoic ring possess estrogenic properties. It was in 1996, Olea et al. [17] found detectable levels on BPA in the saliva of patients who received sealants. However, it is still a controversial topic, as it has not been confirmed by any large-scale study $[16,27]$.

Based on the toxicity of BPA, it has been classified as a category 3 toxic substance and a significant risk factor in human fertility. However, concern is not focused exclusively at molecular level. A significant effect on psychosocial health of children is being reported from a recently published study measuring the exposure from BPA derivatives such as composite

Corresponding author: Crystal Runa Soans (ORCID: https://orcid.org/0000-0001-8781-7678), Nitte (Deemed to be) University, AB Shetty Memorial Institute of Dental Sciences, Department of Orthodontics and Dentofacial Orthopedics, Deralakatte, Mangalore, India, tel.9611200050, e-mail: drcrystalsoans@gmail.com

(C) Copyright by the National Institute of Public Health NIH - National Research Institute 
resins. Higher levels of anxiety, depression and social stress in children was reported with higher levels and longer exposure (5 years) to dental composite resins [14]. Furthermore, there are recent studies done on dental staff indicating more reports of allergic contact dermatitis among them $[9,10,11,15,24]$.

With such level of existing evidence of prolonged release of BPA and associated side effects affecting both mental and physical health, it is very essential to minimize the exposure to BPA while use of dental products and services. For this, mainly private practitioners play a pivotal role to minimize the exposure of BPA to their patients, assistants and themselves in their private clinical practice. Since most private practitioners attend continuous dental education programs from time to time, we expect them to be updated with the knowledge and practice related ill effects of BPA. Their attitude towards patient care and self-care from exposure to BPA needs to be assessed along with knowledge and practice to impart better education through such programs. There are studies which assess all of these among specialists in dental colleges but hardly any studies on private practitioners which cater to the majority of the general population. Hence this questionnaire survey was needed to assess the knowledge, attitude and practice based on exposure and handling of Bisphenol A containing materials among dental surgeons for better understanding about the level of care rendered to the patients and sensitivity towards the ill effects of BPA from dental products.

\section{MATERIAL AND METHODS}

\section{Study sample}

This cross-sectional questionnaire study was carried out in Southern India. Further, a questionnaire was circulated online (Google forms format) amongst the sample group which consists of all private dental surgeons working in private dental clinics across South Indian states of Karnataka and Kerala. A statistically calculated sample size of 400 practitioners who have been practicing and holding a minimum undergraduate level of qualification (BDS) were included in the study.

\section{Validation survey}

The questionnaire was subjected to face and content validation by 3 dental faculties and each question was rated using a 5 point Likert scale to test content validity with range from very important to not important. Questionnaire was tested by 25 randomly selected private dental surgeons for the validity of the survey. Ethical clearance for this study was obtained from Institutional Review Board (ABSM/EC/53/2020).

\section{Questionnaire content}

A consent form with brief study description and a Questionnaire was circulated among the sample group and responses were compiled digitally in google forms. The survey form collected basic demographic data such as name, age, gender, qualification, if attached to dental college or not. The questionnaire consisted of 20 objective type questions out of which ten questions assessed knowledge and five questions assessed the attitude and five questions to understand the practice related measures taken by the dentist. A sample questionnaire is given below.

\section{SAMPLE QUESTIONNAIRE:}

\section{Questionnaire: \\ Demographic details:}

Age: ______ Years

\section{Gender: $\mathrm{M} / \mathrm{F}$}

Educational Qualification: BDS

MDS (Mention Specialty)

No. of years into practice:

- 1-5 years

- 5-10 years

- 10-15years

- 15-20years

- >20 years

Are you attached to a dental college: Yes/No

If Yes, What is your designation: Tutor/ Senior Lecturer/ Reader/ Associate Professor/Professor

\section{QUESTIONS}

\section{Knowledge based:}

1. BPA is an important constituent of $?$
a. Restorative composite
b. Amalgam
c. Impression materials
d. Don't know

2. Sensitivity/ill effects due to BPA exposure is seen more in
a. Males
b. Females
c. Equally susceptible
d. Don't know

3. BPA is a product leached out of which of the following?
a. Orthodontic adhesives
b. Dental composite resin
c. Prosthetic crowns
d. All the above
e. None of the above 
4. Soon after a composite restoration, what happens to the concentration of BPA?
a. Increases in saliva
b. Increases in Urine
c. Both the above
d. Don't know

5. Which of the following is a potential side effect of BPA?
a. Developmental defects
b. Infertility
c. Type 2 diabetes
d. All of the above
e. Don't know

6. Does the type of curing light used and the distance between tip and material when cured affect the amount of BPA release from the material?
a. Yes
b. No
c. Don't know

7. BPA release from self-cure resin when compared to light cure resin is
a. More in self cure than light cure
b. Less in self cure than light cure
c. Same in both
d. Don't know

8. Does tooth that have amalgam restorations release BPA?
a. Yes
b. No
c. Don't know

9. BPA can have which of the following actions on human body?
a. Estrogenicity
b. Cytotoxicity
c. Both of the above
d. Don't know

10. Does use of a rubber dam use reduce BPA exposure to patients?
a. Yes
b. No
c. Don't know

\section{Attitude based:}

1. Do you think that BPA exposure can affect the dentist and the dental technician's health apart from the patients?
a. Strongly agree
b. Agree
c. Neutral
d. Disagree
e. Strongly disagree

2. Do you think that there should be awareness campaigns on ill effects of BPA to improve your knowledge and assess the patients under risk from BPA exposure?
a. Strongly agree
b. Agree
c. Neutral
d. Disagree
e. Strongly disagree

3. Would you want to know more on safety measures to be taken by dentists and dental assistants to prevent BPA exposure?
a. Yes
b. No

4. Do you feel the need to follow strict measures to reduce BPA exposure in private clinical practice?
a. Strongly agree
b. Agree
c. Neutral
d. Disagree
e. Strongly disagree

5. Do you think the BPA levels in dental materials should be highlighted by companies for the safety and awareness of the private dental practitioner?
a. Strongly agree
b. Agree
c. Neutral
d. Disagree
e. Strongly disagree

\section{Practice based:}

6. How often do you check the BPA levels in dental restorative materials you use in daily routine?
a. I never check
b. I check it every time
c. I check it sometimes

7. Do you educate your patients about the possible side effects of BPA?
a. Yes
b. No
c. Sometimes

8. Do you take any protective measures for yourself and your dental assistantsto avoid BPA exposure from aerosols developed during dental procedures 
involving dental composites like Orthodontic debonding procedure?
a. Yes
b. No
c. Sometimes

9. Do you prefer composite restoration over amalgam restoration?
a. Always
b. Never
c. Sometimes

10. Do you ask your patients to gargle immediately following intraoral use of dental materials containing BPA?
a. Always
b. Never
c. Sometimes

\section{Statistical analysis}

The data was entered in Microsoft excel and analyzed using SPSS version 23 for descriptive and inferential statistics. Descriptive statistics were expressed in terms of number and percentage. The inferential statistics were analyzed using ANOVA and Pearson's correlation coefficient.

\section{RESULTS}

A total of 402 responses were collected for this online questionnaire survey over a period of 2 months. Mean age of the participants of this survey was $33.06 \pm 6.649$ years. Table 1 shows the distribution of respondents based on gender. Almost equal number of responses were obtained from both genders.

Table 1. Gender based distribution of responses

\begin{tabular}{|c|c|c|c|}
\hline \multicolumn{2}{|c|}{ Variable } & Frequency & Percent \\
\hline \multirow{4}{*}{ Gender } & Male & 200 & 49.8 \\
\cline { 2 - 4 } & Female & 198 & 49.3 \\
\cline { 2 - 4 } & $\begin{array}{c}\text { Do not wish to } \\
\text { specify }\end{array}$ & 4 & 1.0 \\
\hline
\end{tabular}

Table 2 shows the responses of participants indicating their experience or years of practice in their profession. Maximum respondents falling into the category with 1-5 years of experience and least responses obtained from group with 16-20 years of experience
Table 2. Years of practice based responses

\begin{tabular}{|c|c|c|c|}
\hline \multicolumn{2}{|c|}{ Variable } & Frequency & Percent \\
\hline \multirow{4}{*}{$\begin{array}{c}\text { No. of years into } \\
\text { practice }\end{array}$} & $1-5$ years & 213 & 53.0 \\
\cline { 2 - 4 } & $6-10$ years & 88 & 21.9 \\
\cline { 2 - 4 } & $11-15$ years & 61 & 15.2 \\
\cline { 2 - 4 } & $16-20$ years & 8 & 2.0 \\
\cline { 2 - 4 } & $>20$ years & 32 & 8.0 \\
\hline
\end{tabular}

Table 3 and Table 4 show responses obtained from participants indicating if they are attached to a dental college and if yes then the designation they hold in their respective departments.

Table 3. Responses based on attachment to college

\begin{tabular}{|c|c|c|c|}
\hline \multicolumn{2}{|c|}{ Variable } & Frequency & Percent \\
\hline \multirow{2}{*}{$\begin{array}{c}\text { Attached to a } \\
\text { dental college }\end{array}$} & Yes & 151 & 37.6 \\
\cline { 2 - 4 } & No & 251 & 62.4 \\
\hline
\end{tabular}

Table 4. Designation of respondents attached to college

\begin{tabular}{|c|c|c|c|}
\hline \multicolumn{2}{|c|}{ Variable } & Frequency & Percent \\
\hline \multirow{4}{*}{ Designation } & Tutor & 11 & 2.7 \\
\cline { 2 - 4 } & Senior Lecturer & 75 & 18.7 \\
\cline { 2 - 4 } & Reader & 44 & 10.9 \\
\cline { 2 - 4 } & $\begin{array}{c}\text { Associate } \\
\text { professor }\end{array}$ & 16 & 4.0 \\
\cline { 2 - 4 } & Professor & 5 & 1.2 \\
\cline { 2 - 4 } & $\begin{array}{c}\text { Not attached to } \\
\text { college }\end{array}$ & 251 & 62.4 \\
\hline
\end{tabular}

The knowledge of total respondents are summarized in the Table 5 below for all the ten questions based on percentage of correct and incorrect response. 93.5\% gave the correct response that BPA is an important constituent of restorative resin. $90.5 \%$ gave an incorrect response saying males show greater sensitivity/ill effects towards BPA, which isn't true. Almost equal correct and incorrect responses were recorded when asked to choose the material that releases BPA in question number three. 55\% responses were correct and agreed to that concentration of BPA increases in saliva soon after the restoration. When asked about the potential side effects of BPA only $60 \%$ could give a correct response to it. We obtained almost equal correct and incorrect responses to the question which assess knowledge regarding the type of curing light and type of composite resin used, which may result in varying amounts of BPA release. More than 70\% responded correctly when asked whether amalgam use leads to intra-oral release of BPA. Only $38 \%$ could rightly answer that BPA release could cause both cytotoxic and estrogenic effects in our body. Almost $50 \%$ of the dentists are unaware that the use of rubber dams could reduce BPA exposure. 
Table 5. Responses to knowledge based questions

\begin{tabular}{|c|c|c|}
\hline Question & Correct response & Incorrect response \\
\hline 1 & $376(93.5 \%)$ & $26(6.5 \%)$ \\
\hline 2 & $38(9.5 \%)$ & $364(90.5 \%)$ \\
\hline 3 & $186(46.3 \%)$ & $216(53.7 \%)$ \\
\hline 4 & $221(55 \%)$ & $181(45 \%)$ \\
\hline 5 & $162(40.3 \%)$ & $240(59.7 \%)$ \\
\hline 6 & $199(49.5 \% 0$ & $203(50.5 \%)$ \\
\hline 7 & $192(47.8 \%)$ & $210(52.2 \%)$ \\
\hline 8 & $287(71.4 \%)$ & $115(28.6 \%)$ \\
\hline 9 & $153(38.1 \%)$ & $249(61.9 \%)$ \\
\hline 10 & $195(48.5 \%)$ & $207(51.5 \%)$ \\
\hline
\end{tabular}

The responses obtained for the attitude based questions are summarised in the Table 6 below with four questions showing responses based on 5 point Likert scale and one question with yes/no as its response. $56 \%$ of the dentists agreed to the fact that BPA exposure could affect dentists and the dental technicians, whereas $35.6 \%$ were unaware of the potential threat and $10 \%$ disagreed with this fact. $100 \%$ of dentists agreed on conducting awareness campaigns for ill effects of BPA exposure for practitioners. Almost all dentists agreed on following strict measures to reduce BPA exposure and agreed on the fact that companies should highlight the BPA content and its ill effects on their dental products. $95 \%$ of the dentists were willing to know more on the safety measures to be taken by them to reduce BPA exposure to dentists as well as dental assistants.

Table 7 shows the responses obtained to the practice based questions. $75.9 \%$ of participants do not check the BPA levels in the material they use regularly

Table 6. Responses to attitude based questions

\begin{tabular}{|c|c|c|c|c|c|}
\hline Question & SA & A & $\mathrm{N}$ & $\mathrm{D}$ & SD \\
\hline $\begin{array}{l}\text { 11. BPA exposure can affect the dentist and the dental } \\
\text { technician's health apart from the patients }\end{array}$ & $\begin{array}{c}62 \\
(15.4 \%) \\
\end{array}$ & $\begin{array}{c}164 \\
(40.8 \%) \\
\end{array}$ & $\begin{array}{c}143 \\
(35.6 \%) \\
\end{array}$ & $\begin{array}{c}32 \\
(8 \%) \\
\end{array}$ & $\begin{array}{c}1 \\
(2 \%) \\
\end{array}$ \\
\hline $\begin{array}{l}\text { 12. There should be awareness campaigns on ill effects } \\
\text { of BPA to improve your knowledge and assess the } \\
\text { patients under risk from BPA exposure }\end{array}$ & $\begin{array}{c}170 \\
(42.3 \%)\end{array}$ & $\begin{array}{c}232 \\
(57.7 \%)\end{array}$ & 0 & 0 & 0 \\
\hline $\begin{array}{l}\text { 13. Need to follow strict measures to reduce BPA } \\
\text { exposure in private clinical practice }\end{array}$ & $\begin{array}{c}151 \\
(37.6 \%)\end{array}$ & $\begin{array}{c}219 \\
(54.5 \%)\end{array}$ & $\begin{array}{c}32 \\
(8 \%)\end{array}$ & 0 & 0 \\
\hline $\begin{array}{l}\text { 14. BPA levels in dental materials should be } \\
\text { highlighted by companies for the safety and awareness } \\
\text { of the private dental practitioner }\end{array}$ & $\begin{array}{c}220 \\
(54.7 \%)\end{array}$ & $\begin{array}{c}167 \\
(41.5 \%)\end{array}$ & $\begin{array}{c}15 \\
(3.7 \%)\end{array}$ & 0 & 0 \\
\hline \multicolumn{6}{|c|}{ SA - strongly agree, A - agree, $\mathrm{N}$ - neutral, D - disagree, SD - strongly disagree } \\
\hline \multicolumn{2}{|l|}{ Question } & \multicolumn{2}{|c|}{ Yes } & \multicolumn{2}{|c|}{ No } \\
\hline \multicolumn{2}{|c|}{$\begin{array}{l}\text { 15. Want to know more on safety measures to be taken by dentists } \\
\text { and dental assistants to prevent BPA exposure }\end{array}$} & \multicolumn{2}{|c|}{$382(95 \%)$} & \multicolumn{2}{|c|}{$20(5 \%)$} \\
\hline
\end{tabular}

Table 7. Responses to practice based questions

\begin{tabular}{|c|c|c|}
\hline \multicolumn{2}{|l|}{ Question } & Responses \\
\hline \multirow{3}{*}{$\begin{array}{l}\text { 16. How often do you check the BPA levels in dental restorative } \\
\text { materials you use in your daily routine? }\end{array}$} & I never check & $305(75.9 \%)$ \\
\hline & I check it every time & $3(0.7 \%)$ \\
\hline & I check it sometimes & $94(23.4 \%)$ \\
\hline \multirow{3}{*}{$\begin{array}{l}\text { 17. Do you educate your patients about the possible side effects of } \\
\text { BPA? }\end{array}$} & Yes & $11(2.7 \%)$ \\
\hline & No & $289(71.9 \%)$ \\
\hline & Sometimes & $102(25.4 \%)$ \\
\hline \multirow{3}{*}{$\begin{array}{l}\text { 18. Do you take any protective measures for yourself and your } \\
\text { dental assistants to avoid BPA exposure from aerosols developed } \\
\text { during dental procedures involving dental composites like } \\
\text { Orthodontic debonding procedure? }\end{array}$} & Yes & $131(32.6 \%)$ \\
\hline & No & $208(51.7 \%)$ \\
\hline & Sometimes & $63(15.7 \%)$ \\
\hline \multirow[t]{3}{*}{ 19. Do you prefer composite restoration over amalgam restoration? } & Always & $216(53.7 \%)$ \\
\hline & Never & $25(6.2 \%)$ \\
\hline & Sometimes & $161(40 \%)$ \\
\hline \multirow{3}{*}{$\begin{array}{l}\text { 20. Do you ask your patients to gargle immediately following } \\
\text { intraoral use of dental materials containing BPA? }\end{array}$} & Always & $111(27.6 \%)$ \\
\hline & Never & $117(29.1 \%)$ \\
\hline & Sometimes & $174(43.3 \%)$ \\
\hline
\end{tabular}


in their practice. $71.9 \%$ of participants have never informed their patients about BPA and its side effects but interestingly $25.4 \%$ did sometimes inform their patients about the same. Almost 52\% of participants did not take any protective measures for BPA exposure during dental procedures. Over $53.7 \%$ participants did prefer composite restoration over amalgam but almost $40 \%$ still sometimes used amalgam, while $6 \%$ don't prefer amalgam restoration at all. Almost 30\% of practitioners never asked their patients to gargle immediately after use of BPA-containing products, while $43.3 \%$ did sometimes ask their patients to gargle immediately.

As shown in Table 8, differences in the knowledge, attitude and practice (KAP) behaviour of the participants was analysed. Significant difference was observed in the KAP of participants based on their gender. Females displayed higher knowledge and attitude than males. However, the behaviour of participants not willing to disclose their gender was positive followed by males.

A significant difference was observed in the KAP of participants based on their years of practice. Participants with $>20$ years of practice had a higher level of knowledge and those with 16-20 years of practice had the least knowledge. However, those with 16-20 years of practice displayed a better attitude and behaviour. Those with $>20$ years of practice displayed a least positive attitude and participants with 6-10 years of practice had the least positive behaviour.

A significant difference was observed in the KAP of participants based on their years of practice. Senior lecturers had a higher knowledge level and professors had the least knowledge. Professors displayed a higher attitude and behaviour whereas tutors displayed the least positive attitude and senior lecturers displayed the least positive behaviour.

The correlation between knowledge, attitude and behaviour showed that there was a negative correlation which was statistically significant. It showed that as knowledge increased, the attitude and behaviour decreased. As attitude increased, knowledge and behaviour decreased. As behaviour increased, knowledge and attitude decreased (Table 9). This shows that in spite of having good knowledge regarding harmful effects of BPA, dental surgeons are not very keen while handling materials containing them.

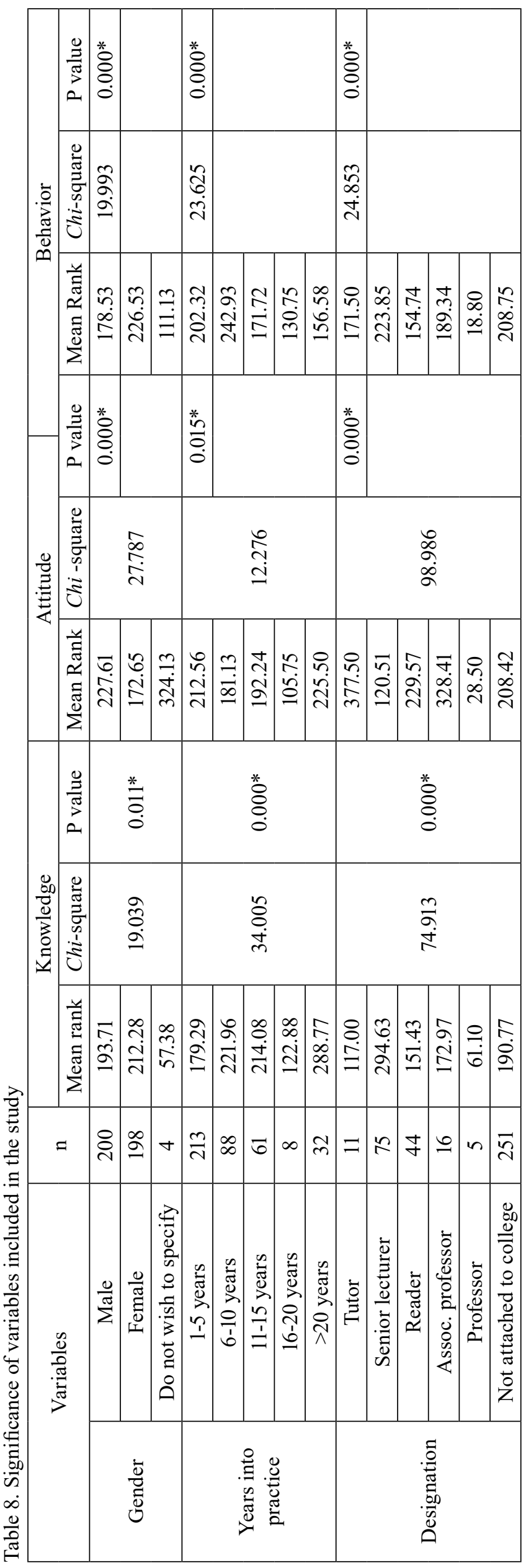


Table 9: Significance of correlations among the variables

\begin{tabular}{|c|c|c|c|c|}
\hline \multirow{3}{*}{ Knowledge } & Knowledge & Attitude & Behaviour \\
\cline { 2 - 5 } & Pearson correlation & 1 & $-0.286^{* *}$ & $-0.131^{* *}$ \\
\cline { 2 - 5 } & Sig. (2-tailed) & & 0.000 & 0.008 \\
\hline \multirow{3}{*}{ Attitude } & $\mathrm{n}$ & 402 & 402 & 402 \\
\cline { 2 - 5 } & Pearson correlation & $-0.286^{* *}$ & 1 & -0.065 \\
\cline { 2 - 5 } & Sig. (2-tailed) & 0.000 & & 0.191 \\
\hline \multirow{3}{*}{ Behaviour } & $\mathrm{n}$ & $-0.131^{* *}$ & -0.065 & 402 \\
\cline { 2 - 5 } & Pearson correlation & 0.008 & 0.191 & 1 \\
\cline { 2 - 5 } & Sig. (2-tailed) & 402 & 402 & 402 \\
\hline **- correlation is significant at the 0.01 level (2-tailed). & \multicolumn{3}{|l}{} \\
\cline { 2 - 5 }
\end{tabular}

\section{DISCUSSION}

The aim of the present study was to evaluate the knowledge, attitude, and practice-based behaviour amongst dental surgeons who cater the majority of the general population in any community. We intended to reach out to the dentists practicing in South Indian states of Karnataka and Kerala to assess their knowledge, attitude and what they practiced regarding BPA, as it is used on a daily basis in dentistry. The outcomes of this survey could further be used to evaluate the need for special instructions on materials containing BPA to be promoted among them. It also reflects whether the controversies regarding BPA is taught to the practitioners in their academic course and also sometimes as a part of continuing dental education $(\mathrm{CDE})$ program which is the major source to update the existing practitioners.

We hypothesized that South Indian dentists know adequately about BPA and its ill effects from dental exposure. Private dental practitioners play a pivotal role in minimizing exposure of BPA to the majority of the population and be able to address any queries or worries expressed by patients.

We observed in our study that females showed higher knowledge and attitude towards exposure to BPA which was statistically significant when compared to males. We deduce that female dentists are more cautious about health issues arising due to BPA exposure. This is consistent with another study about BPA, where females were also found to show greater concern about it. ${ }^{4}$ Several studies suggest that women are more engaged in seeking health information and discussing health related issues $[1,5,19]$.

Swan et al. [25] and Braun et al. [3] evaluated the effects of BPA on endocrine system, and concluded that it affected the fetal brain development. They found that it also altered behaviour in toddlers because of its effects on fetal sex hormones. Furthermore, it is thought to increase the risk of abortion, cause defects in the male genitalia, and increase the risk of asthma in children [20]. Studies shows that BPA acts as thyroid antagonist in rats and mice, altering the hormones produced by the gland $[22,28]$.

A significant difference was observed in the knowledge, attitude and practice of participants based on their years of practice in dentistry. Our results show that dentists with more than 20 years of practice had a higher level of knowledge. Though most of the groups agreed fairly on safety practice to be undertaken related to BPA exposure in their clinics, the ones with experience more than 20 years displayed the least positive attitude and dentists with 6-10 years of practice had the least positive behaviour among all. This could be probably because as experience in the field increases, the knowledge acquired over the period may be more that the ones with less experience, but what makes this finding more interesting is that the group with higher knowledge showed least positive attitude towards BPA containing products and its effects in their private practice. This can be correlated to the fact that there might be no direct effect on patients for which dentists tend to be more careless.

Marzouk et al. [26] conducted a systematic review and their findings suggested that there was an increase in urinary BPA concentrations short term after dental treatment with any type of resin-based material. However, the extent to which it may affect the health of patients is unclear. Bellinger et al. [2] compared the behaviour of children who received composite and amalgam fillings. They found worse psychosocial behaviour in children who received composite fillings. In contrast, there are numerous studies stating that patient exposure to BPA from dental materials is negligible to cause any health hazards $[1,5,7,13]$.

Our assumption for the group of dental surgeons who are attached to the college was confirmed with our study findings, which shows that professors had highest knowledge, attitude and practice behaviour and the junior faculty had lesser knowledge, attitude and practice behaviour. This could be attributed to the fact, being senior faculties and attached to the college, 
they could be more involved with research activity and be updated with the current research findings which will help them to be more sensitive towards their patients and reduce their patient exposure to BPA.

While analysing the results of responses to practicebased behaviours of the dentists, it was clear that most of them had a negative behaviour where they did not find out the BPA content of the material they use, did not educate the patient about BPA exposure nor did they take enough safety measure for themselves and for their assistant. Dentists showed higher inclination towards use of composite over amalgam which again is a contributing factor to BPA exposure, but it can be reduced by the use of rubber dam, gargling the mouth with water soon after the procedure. But the majority of the participants did not know that rubber dam could reduce BPA exposure as we asked about the same in a knowledge based question, whereas many dentists did ask their patients to gargle their mouths.

Most of the uncured monomers is present in the superficial layers of incompletely cured resin. Hence, eliminating this layer using prophylaxis cup [21], rubber dam application [6], and gargling for 30 seconds with water immediately after the placement of composite fillings could reduce the potential BPA exposure [23]. It is important to note that, increasing the distance between curing light-tip to composite, or reducing the curing time, can significantly increase BPA release [18]. We strongly recommend the need to improve the awareness and behaviour towards BPAcontaining dental materials to further decrease BPA exposure. This can be mainly done by promoting lectures or $\mathrm{CDE}$ programs for all the existing practitioners from time to time. From our study we can see a negative correlation between knowledge, attitude and behaviour among the dental surgeons. A thorough strategy needs to be implemented to improve the attitude and behaviour of the dental fraternity and for a greater good for the community by reducing BPA exposure from dental treatments.

\section{CONCLUSIONS}

In spite of having a good knowledge regarding the harmful effects of BPA, dental surgeons are not very cautious while using materials containing them on a regular basis. Therefore, there is a need to enhance the awareness with the help of Continuing Dental Education programs or proper instructions on the packaging.

\section{Conflict of interest}

None.

\section{REFERENCES}

11. Atkinson JC, Diamond F, Eichmiller F, Selwitz $R$, Jones G.: Stability of bisphenol A, triethylene-glycol dimethacrylate, and bisphenol A dimethacrylate in whole saliva. Dent Mater. 2002;18:128-35.

12. Bellinger DC, Trachtenberg F, Zhang A, Tavares $M$, Daniel D, McKinlay S.: Dental amalgam and psychosocial status: The New England children's amalgam trial. J Dent Res. 2008;87:470-4.

13. Braun JM, Yolton K, Dietrich KN, Hornung $R$, Ye X, Calafat $A M$, et al.: Prenatal bisphenol A exposure and early childhood behavior. Environ Health Perspect. 2009;117:1945-52.

14. Brewer PR, Ley BL.: Multiple exposures: Scientific controversy, the media, and public responses to Bisphenol A. Science Communication. 2011;33(1):7697.

15. Ek S.: Gender differences in health information behaviour: a Finnish population-based survey. Health Promotion International. 2015;30(3):736-45.

16. Fleisch AF, Sheffield PE, Chinn C, Edelstein BL, Landrigan PJ.: Bisphenol A and related compounds in dental materials. Pediatrics. 2010;126:760-8.

17. Fung EY, Ewoldsen NO, St Germain HA, Jr, Marx DB, Miaw $C L$, Siew $C$, et al:: Pharmacokinetics of bisphenol A released from a dental sealant. J Am Dent Assoc. 2000;131:51-8.

18. Howe SR, Borodinsky L, Lyon SR.: Potential exposure to Bisphenol A from food contact use of epoxy coated cans. J Coatings Technol 1998;70:69-74.

19. Kanerva L, Estlander T, Jolanki R.: Allergic contact dermatitis from dental composite resins due to aromatic epoxy acrylates and aliphatic acrylates. Contact Dermatitis 1989;20:201-11.

20. Kanerva L, Henriks-Eckerman M-L, Estlander T, Jolanki R, Tarvainen K.: Occupational allergic contact dermatitis and composition of acrylates in dental bonding systems. J Eur Acad Dermatol Venereol1994;3:157-69.

21. Kanerva L, Turjanmaa K, Estlander T, Jolanki R.: Occupational allergic contact dermatitis caused by 2-hydroxyethyl methacrylate (2-HEMA) in a new dentin adhesive. Am J Cont Dermatol 1991;2:2430.

22. Lorence D, Park H.: Gender and online health information: a partitioned technology assessment. Health Information \& Libraries Journal. 2007;24(3):204-9.

23. Manoj MK, Ramakrishnan R, Babjee S, Nasim R.: High-performance liquid chromatography analysis of salivary bisphenol A levels from light-cured and chemically cured orthodontic adhesives. Am J Orthod Dentofacial Orthop. 2018;154:803-8.

24. Maserejian N, Trachtenberg F, Hauser R, et al.: Dental composite restorations and psychosocial function in children. Pediatrics2013;130:328-38.

25. Munksgaard E.: Toxicology versus allergy in restorative dentistry. Adv Dent Res 1999;6:17- 21.

26. Nathanson D, Lertpitayakun P, Lamkin MS, Edalatpour $M$, Chou LL.: In vitro elution of leachable components from dental sealants. J Am Dent Assoc 1997;128:151723. 23 . 
27. Olea N, Pulgar R, Olea-Serrano F, Rivas A, NovilloFertrell A, Pedraza $V$, et al.: Estrogenicity of resinbased composites and sealant used in dentistry. Environ Health Perspect 1996;104: 298-305.

28. Purushothaman D, Kailasam V, Chitharanjan AB.: Bisphenol A release from orthodontic adhesives and its correlation with the degree of conversion. Am J Orthod Dentofacial Orthop. 2015;147:29-36.

29. Renahy E, Parizot I, Chauvin P.: Determinants of the frequency of online health information seeking: Results of a Web-based survey conducted in France in 2007. Informatics for Health and Social Care. 2010;35(1):2539.

30. Rochester JR.: Bisphenol A and human health: A review of the literature. ReprodToxicol. 2013;42:132-55.

31. Rueggeberg FA, Dlugokinski M, Ergle JW.: Minimizing patients' exposure to uncured components in a dental sealant. J Am Dent Assoc. 1999;130:1751-7.

32. Seiwa C, Nakahara J, Komiyama T, Katsu Y, Iguchi T, Asou $H$, et al: Bisphenol A exerts thyroid-hormonelike effects on mouse oligodendrocyte precursor cells. Neuroendocrinology. 2004;80:21-30.

33. Silikas $N$, Eliades $G$, Watts DC.: Light intensity effects on resin-composite degree of conversion and shrinkage strain. Dent Mater. 2000;16:292-6.
34. Slavin RG, Ducomb DF.: Allergic contact dermatitis. Hosp Pract1999;30:39-51.

35. Swan SH, Liu F, Hines M, Kruse RL, Wang C, Redmon $\mathrm{JB}$, et al. Prenatal phthalate exposure and reduced masculine play in boys. Int J Androl. 2010;33:259-69.

36. Marzouk T., S. Sathyanarayana, A.S. Kim, A.L. Seminario, and C.M. McKinney: A Systematic Review of Exposure to Bisphenol A from Dental Treatment. JDR Clin \& Trans Res. 2019;4(2):106-115.

37. Zampeli D, Papagiannoulis L, Eliades $G$, Pratsinis $H$, Kletsas D, Eliades T.: In vitro estrogenicity of dental resin sealants. Pediatr Dent 2012;34:312-6.

38. Zoeller RT, Bansal R, Parris C.: Bisphenol-A, an environmental contaminant that acts as a thyroid hormone receptor antagonist in vitro, increases serum thyroxine, and alters $\mathrm{RC} 3 /$ neurogranin expression in the developing rat brain. Endocrinology. 2005;146:607-12.

Received: 09.08.2021

Accepted: 13.09 .2021

Published online first: 22.09.2021 